\title{
Policy in Clinical Practice: Medicare Advantage and Observation Hospitalizations
}

\author{
Farah Acher Kaiksow, MD, MPP1,2*, W Ryan Powell, MA, PhD2,3, Claire K Ankuda, MD, MPH4, \\ Amy J H Kind, MD, PhD ${ }^{2,3,5}$, Jonathan B Jaffery, MD, MS ${ }^{6}$, Charles F S Locke, MDㄱ, Ann M Sheehy, MD, MS²,8
}

\begin{abstract}
'Department of Medicine, Division of Hospital Medicine, University of Wisconsin School of Medicine and Public Health, Madison, Wisconsin; ${ }^{2}$ Health Services and Care Research Program, University of Wisconsin Department of Medicine, Madison, Wisconsin; ${ }^{3}$ Department of Medicine, Division of Geriatrics and Gerontology, University of Wisconsin School of Medicine and Public Health, Madison, Wisconsin; ${ }^{4}$ Brookdale Department of Geriatrics and Palliative Medicine, Icahn School of Medicine at Mount Sinai, New York, New York; ${ }^{5}$ Department of Veterans Affairs, Geriatrics

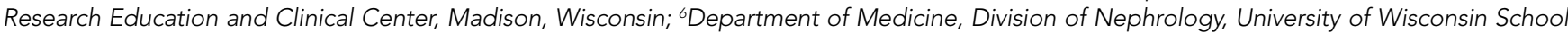
of Medicine and Public Health, Madison, Wisconsin; ${ }^{7}$ Department of Medicine, Division of General Internal Medicine, Johns Hopkins School of Medicine, Baltimore, Maryland; ${ }^{8}$ Department of Medicine, Division of Hospital Medicine, University of Wisconsin School of Medicine and Public Health, Madison, Wisconsin.
\end{abstract}

\section{CLINICAL SCENARIO}

A 73-year-old man presents to the emergency department with sepsis secondary to community-acquired pneumonia. The patient requires supplemental oxygen and is started on intravenous antibiotics. His admitting physician expects he will need more than two nights of hospital care and suggests that inpatient status, rather than outpatient (observation) status, would be appropriate under Medicare's "Two-Midnight Rule." The physician also suspects the patient may need a brief stay in a skilled nursing facility (SNF) following the mentioned hospitalization and notes that the patient has a Medicare Advantage plan (Table) and wonders if the Two-Midnight Rule applies. Further, she questions whether Medicare's "Three-Midnight Rule" for SNF benefits will factor in the patient's discharge planning.

\section{BACKGROUND AND HISTORY}

Since the 1970s, the Centers for Medicare \& Medicaid Services (CMS) has allowed enrollees to receive their Medicare benefits from privately managed health plans through the so-called Medicare Advantage programs. CMS contracts with commercial insurers who, in exchange for a set payment per Medicare enrollee, "accept full responsibility (ie, risk) for the costs of their enrollees' care." 1 Over the past 20 years the percent of Medicare Advantage enrollees has nearly doubled nationwide, from $18 \%$ to $34 \%$, and is projected to grow even further to $42 \%$ by $2028{ }^{2,3}$ The reasons beneficiaries choose to enroll in Medicare Advantage over Traditional Medicare have yet to be thoroughly studied; ease of enrollment and plan administration, as well as lower deductibles, copays, and out-of-pocket maximums for in-network services, are thought to be some of the driving factors.

The federal government has asserted two goals for the development of Medicare Advantage: beneficiary choice and economic efficiency. ${ }^{1}$ Medicare Advantage plans must be

*Corresponding Author: Farah Acher Kaiksow, MD, MPP; E-mail: fkaiksow@ medicine.wisc.edu; Telephone: 608-265-3518

Received: November 19, 2019; Revised: November 23, 2019;

Accepted: November 24, 2019

(๔) 2020 Society of Hospital Medicine DOI 10.12788/jhm.3364 actuarially equal to Traditional Medicare but do not have to cover services in precisely the same way. Medicare Advantage plans may achieve cost savings through narrower networks, strict control of access to SNF services and acute care inpatient rehabilitation, and prior authorization requirements, the latter of which has received recent congressional attention., On the other hand, many Medicare Advantage plans offer dental, fitness, optical, and caregiver benefits that are not included under Traditional Medicare. Beneficiaries can theoretically compare the coverage and costs of Traditional Medicare to Medicare Advantage programs and make informed choices based on their individualized needs. The second stated goal for the Medicare Advantage option assumes that privately managed plans provide care at lower costs compared with CMS; this assumption has yet to be confirmed with solid data. Indeed, a recent analysis comparing the overall costs of Medicare Advantage to those of Traditional Medicare concluded that Medicare Advantage costs CMS more than Traditional Medicare, ${ }^{6}$ perhaps in part due to risk adjustment practices.?

\section{POLICY IN PRACTICE}

There are a number of areas of uncertainty regarding the specifics of how Medicare Advantage plans work, including Medicare Advantage programs' use of outpatient (observation) stays. CMS has tried to provide guidance to healthcare organizations and clinicians regarding the appropriate use of inpatient hospitalizations for patients with Traditional Medicare, including the implementation of the Two-Midnight Rule in 2013. According to the rule, clinicians should place inpatient admission orders when they reasonably expect a patient's care to extend across two midnights. ${ }^{8}$ Such admission decisions are subject to review by Medicare contractors and Quality Improvement Organizations.

In contrast, Medicare Advantage plans which enter into contracts with specific healthcare systems are not required to abide by CMS' guidelines for the Two-Midnight Rule. ${ }^{9}$ When Medicare Advantage firms negotiate contracts with individual hospitals and healthcare organizations, CMS has been clear that such contracts are not required to include the Two-Midnight Rule when it comes to making hospitalization status decisions. ${ }^{10}$ Instead, in these instances, Medicare Advantage plans 


\begin{tabular}{|c|c|}
\hline Term & Definition \\
\hline Traditional, Original, or Fee-for-Service Medicare & $\begin{array}{l}\text { Usually refers to Parts A and B healthcare coverage for those over Age } 65 \text { and younger patients with } \\
\text { disabilities or end-stage renal disease requiring dialysis, provided directly through the Centers for } \\
\text { Medicare \& Medicaid Services (CMS). Both Parts A and B have deductibles and copays associated } \\
\text { with their coverage; these amounts vary by year and by the amount of time a beneficiary paid into } \\
\text { the system. }\end{array}$ \\
\hline Medicare Part A & $\begin{array}{l}\text { Covers inpatient/hospital expenses for beneficiaries admitted to the hospital as inpatients and for } \\
\text { postacute skilled nursing facility coverage for qualifying beneficiaries with an inpatient stay that } \\
\text { crosses three midnights. }\end{array}$ \\
\hline Medicare Part B & Covers outpatient/clinic expenses, including outpatient (observation) hospitalizations. \\
\hline Medicare Part C/Medicare Advantage Plan & $\begin{array}{l}\text { Medicare Advantage plans are approved by CMS but offered through commercial insurance } \\
\text { companies. These plans combine Medicare Parts A and B into a single plan and cover prescription } \\
\text { drugs. Individuals enrolled in Medicare Advantage plans are still enrolled in Medicare, but receive } \\
\text { their benefits through their Medicare Advantage plans. Medicare Part C/Medicare Advantage costs } \\
\text { vary by plan. }\end{array}$ \\
\hline Medigap & $\begin{array}{l}\text { Commercial insurance supplemental coverage typically used in combination with Traditional } \\
\text { Medicare. }\end{array}$ \\
\hline Inpatient Hospitalization & A hospital stay billed under Medicare Part A under "inpatient status." \\
\hline Outpatient (Observation) Hospitalization & $\begin{array}{l}\text { A hospital stay billed under Medicare Part B under "outpatient status." Although commonly referred } \\
\text { to as "observation status," observation is technically outpatient status with observation services. } \\
\text { Observation hospital care can be delivered anywhere in a hospital, from an observation unit to an } \\
\text { intensive care unit. }\end{array}$ \\
\hline
\end{tabular}

Abbreviation: CMS, Centers for Medicare \& Medicaid Services.

often use proprietary decision tools containing clinical criteria, such as Milliman Care Guidelines or InterQual, and/or their own plan's internal criteria as part of the decision-making process to grant inpatient or outpatient (observation) status. More importantly, CMS has stated that for hospitals and healthcare systems that do not contract with Medicare Advantage programs, the Two-Midnight Rule should apply when it comes to making hospitalization status decisions. ${ }^{10}$

\section{Implications for Patients}

Currently, there are no data available to compare between Medicare Advantage enrollees and traditional medicine beneficiaries in terms of the frequency of observation use and out-of-pocket cost for observation stays. As alluded to in the patient's case, the use of outpatient (observation) status has implications for a patient's posthospitalization SNF benefit. Under Traditional Medicare, patients must be hospitalized for three consecutive inpatient midnights in order to qualify for the SNF benefit. Time spent under outpatient (observation) status does not count toward this three-day requirement. Interestingly, some Medicare Advantage programs have demonstrated innovation in this area, waiving the three inpatient midnight requirement for their beneficiaries; ${ }^{11}$ there is evidence, however, that compared with their Traditional Medicare counterparts, Medicare Advantage beneficiaries are admitted to lower quality SNFs. ${ }^{12}$ The posthospitalization consequences of an inpatient versus outpatient (observation) status determination for a Medicare Advantage beneficiary is thus unclear, further complicating the decision-making process for patients when it comes to choosing a Medicare policy, and for providers when it comes to choosing an admission status.

Implications for Clinicians and Healthcare Systems After performing an initial history and physical exam, if a healthcare provider determines that a patient requires hospitalization, an order is placed to classify the stay as inpatient or outpatient (observation). For beneficiaries with Traditional Medicare or a Medicare Advantage plan that has not contracted with the hospital, clinicians should follow the Two-Midnight Rule for making this determination. For contracted Medicare Advantage, the rules are variable. Under Medicare's Conditions of Participation, hospitals and healthcare organizations are required to have utilization management (UM) programs to assist physicians in making appropriate admission decisions. UM reviews can happen at any point during or after a patient's stay, however, and physicians may have to make decisions using their best judgment at the time of admission without real-time input from UM teams.

Outpatient (observation) care and the challenges surrounding appropriate status orders have complicated the admission decision. In one study of 2014 Traditional Medicare claims, almost half of outpatient (observation) stays contained a status change. ${ }^{13}$ Based on a recent survey of hospitalist physicians, about two-thirds of hospitalists report at least monthly requests from patients to change their status. ${ }^{14}$ Hospital medicine physicians report that these requests "can severely damage the therapeutic bond"14 between provider and patient because the provider must assign status based on CMS rules, not patient request. 


\section{COMMENTARY AND RECOMMENDATIONS}

CMS could improve the current system in one of two ways. First, CMS could require that all Medicare Advantage plans follow the same polices as Traditional Medicare policies regarding the Two- and Three-Midnight Rules. This would eliminate the need for both hospitals and healthcare organizations to dedicate time and resources to negotiating with each Medicare Advantage program and to managing each Medicare Advantage patient admission based on a specific contract. Ideally, CMS could completely eliminate its outpatient (observation) policy so that all hospitalizations are treated exactly the same, classified under the same billing status and with beneficiaries having the same postacute benefit. This would be consistent with the sentiment behind the recent Office of Inspector General's (OIG) report suggesting that CMS consider counting outpatient midnights toward the three-midnight requirement for postacute SNF care "so that beneficiaries receiving similar hospital care have similar access to these services." 15

\section{WHAT SHOULD I TELL MY PATIENT?}

The physician in the example above should tell their patient that they will be admitted as an inpatient given her expectation that the patient will need hospitalization for oxygen support, parenteral antibiotics, and evaluation by physical therapy to determine a medically appropriate discharge plan. The physician should document the medical necessity for the admission, specifically her expectation that the patient will require at least two midnights of medically necessary hospital care. If the patient has Traditional Medicare, this documentation, along with the inpatient status order, will fulfill the requirements for an inpatient stay. If the patient has a Medicare Advantage plan, the physician can advise the patient that the plan administrators will ultimately determine if an inpatient stay will be covered or denied.

\section{CONCLUSIONS}

In the proposed clinical scenario, the rules determining the patient's hospitalization status depend on whether the hospital contracts with the patient's Medicare Advantage plan, and if so, what the contracted criteria are in determining inpatient and outpatient (observation) status. The physician could consider real-time input from the hospital's UM team, if available. Regardless of UM input, if the physician hospitalizes the patient as an inpatient, the Medicare Advantage plan administrators will make a determination regarding the appropriateness of the admission status, as well as whether the patient qualifies for posthospitalization Medicare SNF benefits (if requested) and, additionally, which SNFs will be covered. If denied, the hospitalist will have the option of a peer-to-peer discussion with the insurance company to overturn the denial. Given the confusion, complexity, and implications presented by this admission status decision-making process, standardization across Traditional Medicare and Medicare Advantage plans, or a budget-neutral plan to eliminate status distinction altogether, is certainly warranted.

Disclosures/Funding: Dr. Sheehy received a stipend in support of the Next Step series from the ABIM Foundation which ended in January 2018. Dr. Ankuda's institution received a grant from the National Palliative Care Research Center during the conduct of this work. Dr. Kind receives grant funding and other support from the National Institutes of Health-National Institute on Minority Health and Health Disparities and National Institute on Aging, the US Department of Veterans Affairs and the University of Wisconsin Department of Medicine Health Services and Care Research Program. All other authors have nothing to disclose.

\section{References}

1. McGuire TG, Newhouse JP, Sinaiko AD. An economic history of Medicare Part C. Millbank O. 2011;89(2):289-332. https://doi.org/10.1111/j.14680009.2011.00629.x.

2. Medicare Advantage. Available at: https://www.kff.org/medicare/fact-sheet/ medicare-advantage/.

3. Neuman P, Jacobson G. Medicare Advantage checkup. N Engl J Med. 2018;379(22):2163-2172. https://doi.org/10.1056/NEJMhpr1804089.

4. HR 3107: improving seniors' timely access to Care Act of 2019. Available at: https://www.congress.gov/bill/116th-congress/house-bill/3107/text?q=\%7B\%22search\%22\%3A\%5B\%22prior+authorization\%22\%5D\%7D\&r=1\&s=1.

5. Gadbois EA, Tyler DA, Shield RR, et al. Medicare Advantage control of postacute costs: perspective from stakeholders. Am J Manag Care. 2018;24(12):e386-e392.

6. Rooke-Ley H, Broome T, Mostashari F, Cavanaugh S. Evaluating Medicare programs against saving taxpayer dollars. Health Affairs, August 16, 2019. Available at: https://www.healthaffairs.org/do/10.1377/hblog20190813.223707/ full/.

7. Office of Inspector General. Billions in estimated Medicare Advantage payments from chart reviews raise concerns. December 2019. Available at: https://oig.hhs.gov/oei/reports/oei-03-17-00470.pdf. Accessed December 15, 2019.

8. Fact sheet: two-midnight rule. Available at: https://www.cms.gov/newsroom/ fact-sheets/fact-sheet-two-midnight-rule-0.

9. Locke $\mathrm{C}, \mathrm{Hu}$ E. Medicare's two-midnight rule: what hospitalists must know. Available at: https://www.the-hospitalist.org/hospitalist/article/194971/ medicares-two-midnight-rule.

10. Announcement of calendar year (CY) 2019 Medicare Advantage capitation rates and Medicare Advantage and part D payment policies and final call letter. Page 206. Available at: https://www.cms.gov/Medicare/Health-Plans/ MedicareAdvtgSpecRateStats/Downloads/Announcement2019.pdf. Accessed November 18, 2019.

11. Grebla R, Keohane L, Lee Y, Lipsitz L, Rahman M, Trivedi A. Waiving the three-day rule: admissions and length-of-stay at hospitals and skilled nursing facilities did not increase. Health Aff. 2015;34(8):1324-1330. https://doi. org/10.1377/hlthaff.2015.0054.

12. Meyers $D$, Mor $V$, Rahman M. Medicare Advantage enrollees more likely to enter lower-quality nursing homes compared to fee-for-service enrollees. Health Aff. 2018;37(1):78-85. https://doi.org/10.1377/hlthaff.2017.0714.

13. Sheehy A, Shi F, Kind AJH. Identifying observation stays in Medicare data: Policy implications of a definition. J Hosp Med. 2019;14(2):96-100. https:// doi.org/10.12788/jhm.3038

14. The hospital observation care problem: perspectives and solutions from the Society of Hospital Medicine. Available at: https://www.hospitalmedicine.org/globalassets/policy-and-advocacy/advocacy-pdf/shms-observation-white-paper-2017. Accessed November 18, 2019.

15. U.S. Department of Health \& Human Services, Office of Inspector General. Solutions to reduce fraud, waste and abuse in HHS programs: OIG's top recommendations. Available at: https://oig.hhs.gov/reports-and-publications/ compendium/. Accessed November 22, 2019. 